\title{
Evaluation of the influence of the windbreak trees on the change of wind shear in weakly complex terrains
}

\author{
Angel Terziev ${ }^{1 *}$, Yancho Panteleev ${ }^{1}$, Iliya $_{\text {Iliev }}^{2}$ and Hristo Beloev ${ }^{2}$ \\ ${ }^{1}$ Department of Power Engineering and Power Machines, Technical University of Sofia, 8 Kliment \\ Ohridski blvd., 1000 Sofia, Bulgaria \\ ${ }^{2}$ University of Ruse, Department of Thermotechnics, Hydraulics and Ecology 7017 Ruse, 8 \\ Studentska Str., Bulgaria
}

\begin{abstract}
The turbulent nature of the wind above the earth's surface depends on both the topology of the terrain and the presence of natural obstacles along the way such as low grasses and shrubs, as well as medium-tall trees. When the wind passes through the indicated obstacles, detachment is observed i.e. formation of large eddies, which are carried away by the main flow, after which they dissipate. The size of the vortices, as well as the period of dissipation, depends on the wind speed, as well as the type of obstacle. The presence of windbreak trees significantly changes the wind shear over the surface, and hence the energy potential of the wind in the vicinity of trees. In present work, the influence of the tree belt on the wind shear at the adopted prevailing wind direction is investigated. The degree of deformation of the speed profile after the obstacle in weakly complex terrain is shown. Relevant prescriptions for the location of wind turbines in the vicinity of windbreak trees are presented in view of minimum shading and maximum energy output.
\end{abstract}

\section{Introduction}

Studying the wind behaviour over terrain is essential for determining the energy potential. Every terrain specific such as hills and elevations, as well as natural and artificial obstacles, affect the distribution of the speed profile in height, which changes the potential of the energy winds. The above factors of varying severity affect the change in velocity distribution on the earth's surface. High hills and elevations lead to the generation of large scale vortices, which, depending on the size, can affect both the distribution of the velocity profile near the earth's surface and at a significant height. Tall vegetation also represents wind resistance, the main purpose of which is to significantly reduce the speed in the surface boundary layer in order to prevent the transfer of planting material from agricultural land. However, this vegetation significantly affects the speed profile in the vicinity of the

*Corresponding author: aterziev@,tu-sofia.bg 
windbreak trees, which is a prerequisite for reduced energy output. Installing a wind turbine in this area would reduce production by up to $20 \%$ depending on the technical characteristics (including tower height) of a wind turbine [2].

Measurements carried out in the vicinity of the tree belt can give a clear idea of the distribution of the wind shear, especially when the terrain is flat. In [1] a comparison was made between experimental and numerical results for the wind speed profile in height, where a good match is observed, especially at a height of up to $50 \mathrm{~m}$. Above this height, however, the differences between measured and predicted results can reach up to $10 \%$.

The use of reference measurements to analyze wind parameters at a considerable distance from the terrain point also does not provide the necessary information on the influence of woody vegetation [2,3]. In [4] an analysis of the influence of the terrain and surrounding vegetation on the wind speed profile in height is presented. The roughness modeling was performed using a WAsP software package. The roughness factor is 0.2 .

Numerical modelling tools can also be used to predict the effect of small obstacles on wind flow turbulence [5]. In this work, a CFD code is presented that can be successfully used for the micro-sitting of wind turbines where the wind flow is affected by these obstacles. A similar study where the numerical procedures are used to study the behaviour of the wind when passing different types of trees is presented in [6]. K- $\varepsilon$ turbulent model is used to predict the impact of the surface roughness on the main wind flow by using $\mathrm{z}_{0}$ function $[7,8]$.

\section{Site specifics and on-site wind data}

\subsection{Site specifics}

The spot, object of the analysis is located in the northeastern part of Bulgaria, where the terrain is weakly complex. The terrain is open in all directions, and there are only windbreak trees with an average height between 15 up to $20 \mathrm{~m}$. Tree species are deciduous trees that represent some significant resistance to wind especially in the vicinity of the surface boundary layer. The nearest settlement Prolez village is located $2.9 \mathrm{~km}$ southwest, and about $2 \mathrm{~km}$ in a northwest direction from the mast is the village of Tvarditsa (source Google map view). Fig. 1 is a representation of the location of the measuring mast, the wind belts (windbreak trees), and the nearest settlements (google maps view). The distance between the mast and the nearest tree is $80 \mathrm{~m}$.

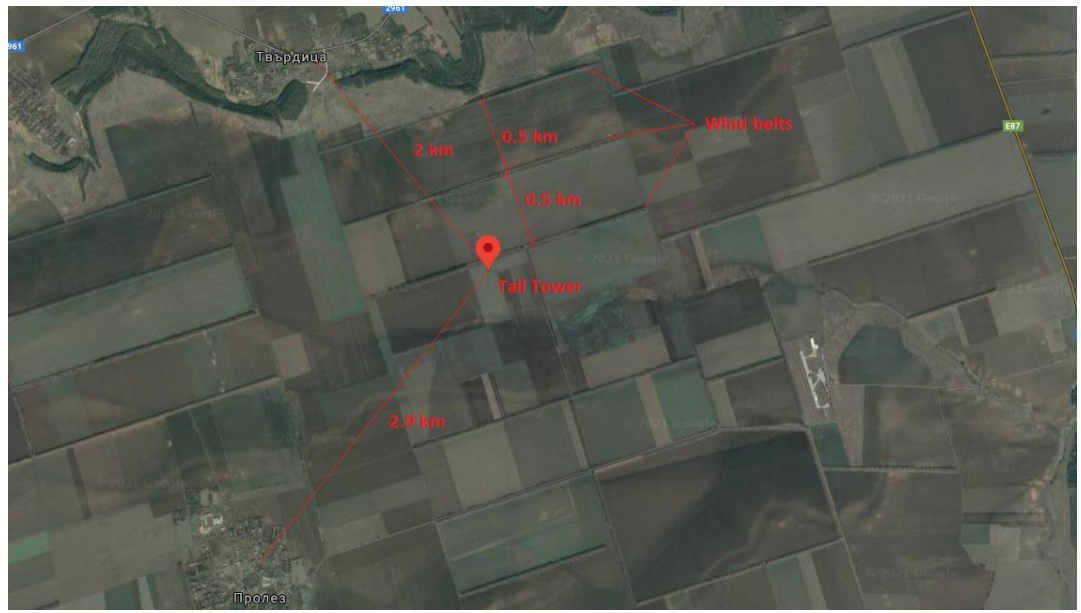

Fig. 1. Google maps view of the location of mast and windbreak trees 


\subsection{Raw wind data analysis}

A tall meteorological mast (60 meters) equipped with calibrated and certified equipment is used to determine the wind potential [3]. Four wind speed sensors were used: two at $60 \mathrm{~m}$, one at $50 \mathrm{~m}$, and 1 sensor at $40 \mathrm{~m}$ height. Two sensors at 60 and $50 \mathrm{~m}$ were used to measure the prevailing wind direction (wind vanes). There is also a temperature sensor installed for measuring the air temperature. Data logger was used to collect wind data - wind data for a three-year period (about 145000 records with 10-mitues mean intervals) were registered. The data processing was done carefully and the freeze periods were eliminated. Table 1 presents the average wind speed at the specified mast heights.

Table 1. Summarized average wind data from on-site measurements

\begin{tabular}{|c|c|c|c|}
\hline Sensor & $\begin{array}{c}\text { Installation } \\
\text { Height, } \mathbf{m}\end{array}$ & Parameter & Value \\
\hline Anemometer & 60 & Wind speed, $\mathrm{m} / \mathrm{s}$ & 5.88 \\
\hline Anemometer & 60 & Wind speed, $\mathrm{m} / \mathrm{s}$ & 5.92 \\
\hline Anemometer & 50 & Wind speed, $\mathrm{m} / \mathrm{s}$ & 5.66 \\
\hline Anemometer & 40 & Wind speed, $\mathrm{m} / \mathrm{s}^{\mathrm{s}}$ & 5.34 \\
\hline Wind vane & 60 & Wind direction, $^{\circ}$ & 201.2 \\
\hline Wind vane & 50 & Wind direction, $^{\circ}$ & 202.2 \\
\hline $\begin{array}{c}\text { Temperature } \\
\text { sensor }\end{array}$ & 10 & Temperature, $^{\circ} \mathrm{C}$ & 13.2 \\
\hline
\end{tabular}

The data from the field measurements show that there are two prevailing wind directions: north-northwest and south-southwest (fig. 2). Further in the analysis, the following two prevailing wind directions and how the wind shear is affected when passing through the tree missives are adopted.

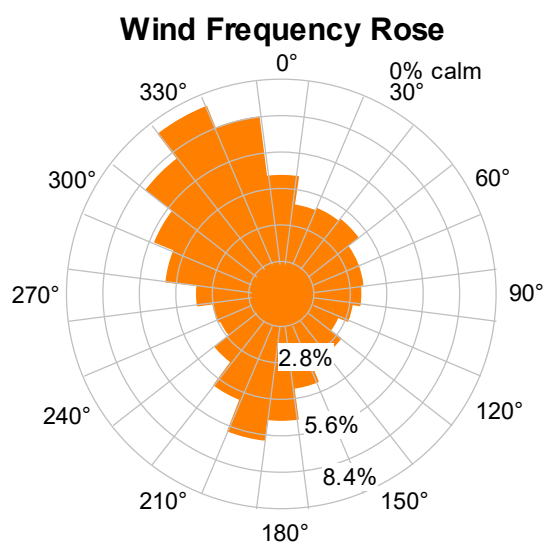

a)

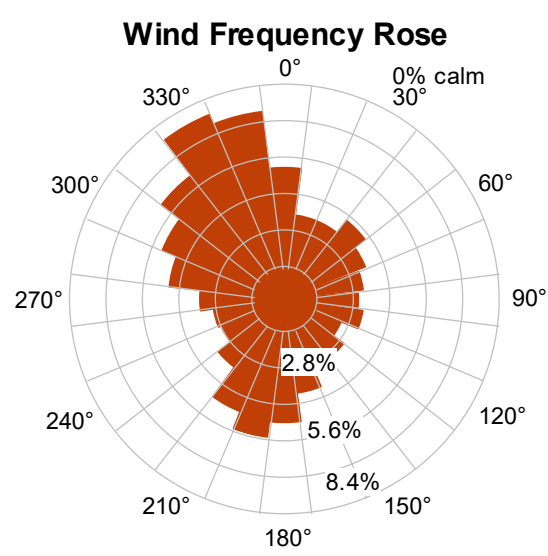

b)

Fig. 2. Prevailing wind direction data a) $60 \mathrm{~m}$ height; b) $50 \mathrm{~m}$ height 


\section{3D topography modeling}

A three-dimensional model of the terrain surface was prepared on the basis of a topographic map. No significant changes in elevation were observed within the considered terrain.

Fig. 3a shows the isolines of the terrain surface. It can be seen that the altitude varies from 20 to $80 \mathrm{~m}$. Fig. $3 \mathrm{~b}$ is a representation of a three-dimensional model with the location of the meteorological mast. In addition, the prevailing wind directions are indicated.

As mentioned above, the main purpose of the work is to show the influence of the existing tree belts on the deformation (distortion) of the wind shear over the terrain. It is known that the topography of the terrain, despite the flat nature, has little effect on the speed profile. For the purpose of the study in fig. $3 \mathrm{c}$ and $\mathrm{d}$ are also shown the terrain profiles along the prevailing wind direction. Fig. $3 \mathrm{c}$ shows that the wind speed will be slightly decreased when the prevailing direction is from the north-northwest, and slightly increased when the prevailing wind direction is from the south-southwest.

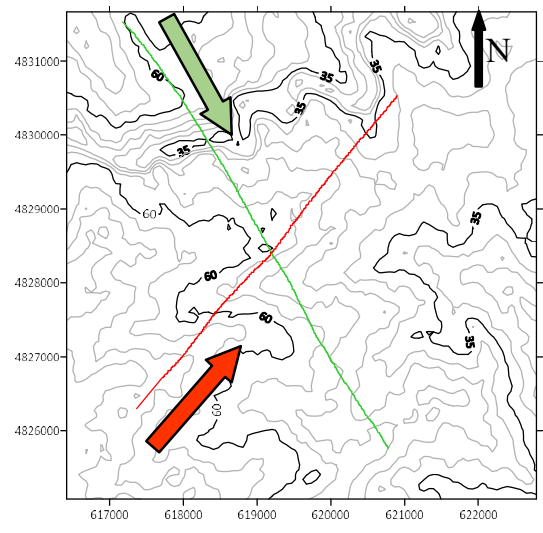

a)

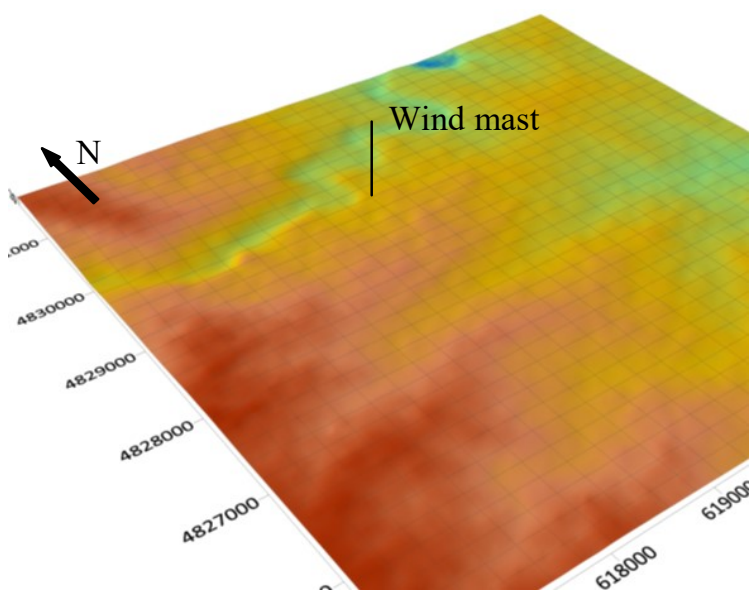

b)

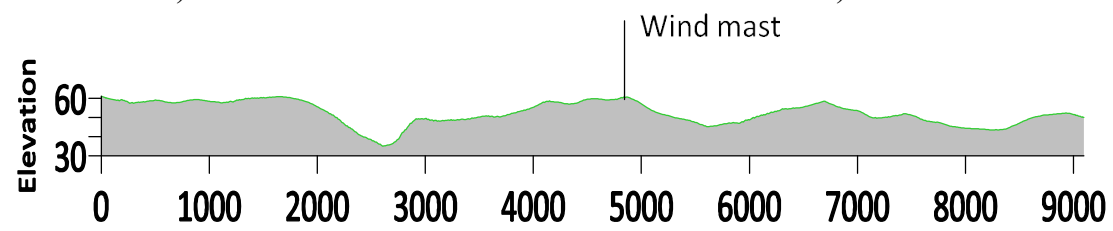

Distance

c)

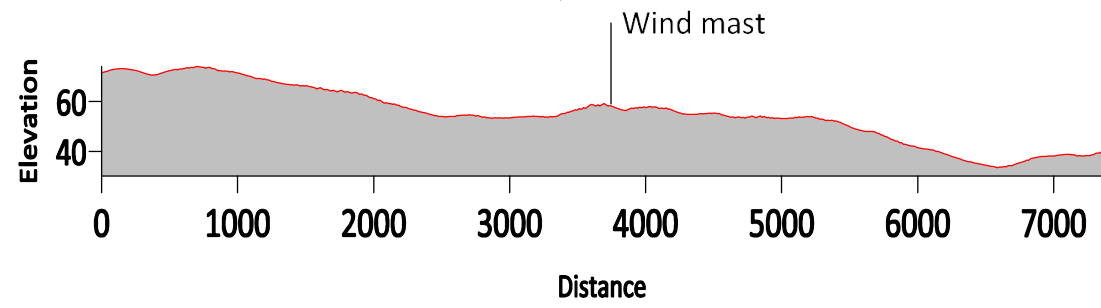

d)

Fig. 3. Terrain specifics: a) Isolines of the terrain with prevailing wind directions; b) 3D terrain orography; c) terrain profile along the noth-norwest prevailing wind direction; d) terrain profile along the south-southwest prevailing wind direction. 


\section{Wind shear analysis}

When the prevailing wind direction is from the north, before the wind reaches the mast, it passes through three windbreaker groups of trees, which are at a distance of about $500 \mathrm{~m}$ from each other. When the prevailing wind direction is from the south, the distance between tree belts and tall tower is about $1300 \mathrm{~m}$ (Fig. 1). An analysis of the wind speed profile in height for the two prevailing wind directions was made, using the data from the measuring instruments at the three heights.

Figure 4 shows the wind speed distribution at the point of the mast after the wind passes through windbreaker trees with a height of $20 \mathrm{~m}$ at a distance of $1.3 \mathrm{~km}$ from the mast. The performed analysis shows that the power-law exponent alpha is 0.314 and the surface roughness factor is $2.0 \mathrm{~m}$ (data obtained with Windographer software). The wind shear distribution shows that the wind profile is not affected by the trees located $1.3 \mathrm{~km}$ away from the mast. The increased velocity in the surface boundary layer is because of the speedup of the flow in terms of site specifics.

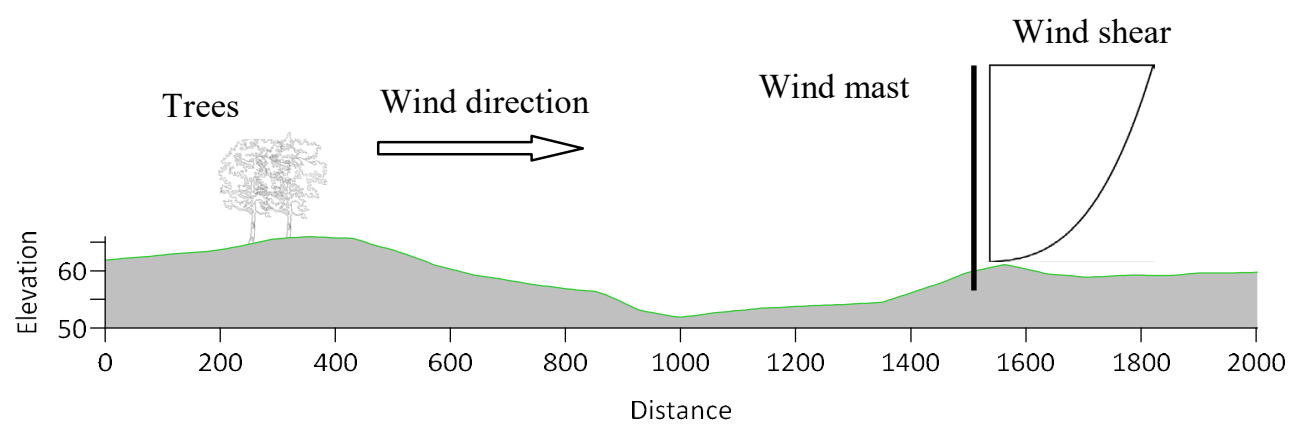

Fig. 4. Wind shear over the terrain at the point of the mast when prevailing wind direction from south-southwestern direction

Figure 5 shows the wind speed distribution at the point of the mast after the wind passes through a couple of windbreaker trees with a height of $20 \mathrm{~m}$ at a distance of $0.5 \mathrm{~km}$ between the separate rows of trees and $80 \mathrm{~m}$ distance between the closest tree row and the mast. The analysis performed shows that the power law exponent alpha is 0.267 and the surface roughness factor is $1.14 \mathrm{~m}$. The wind shear distribution shows that the wind profile is affected significantly close to the surface boundary layer - it can be seen that the wind shear is steeper. Still away from the surface boundary layer and above $50 \mathrm{~m}$ height the wind shear stays unaffected.

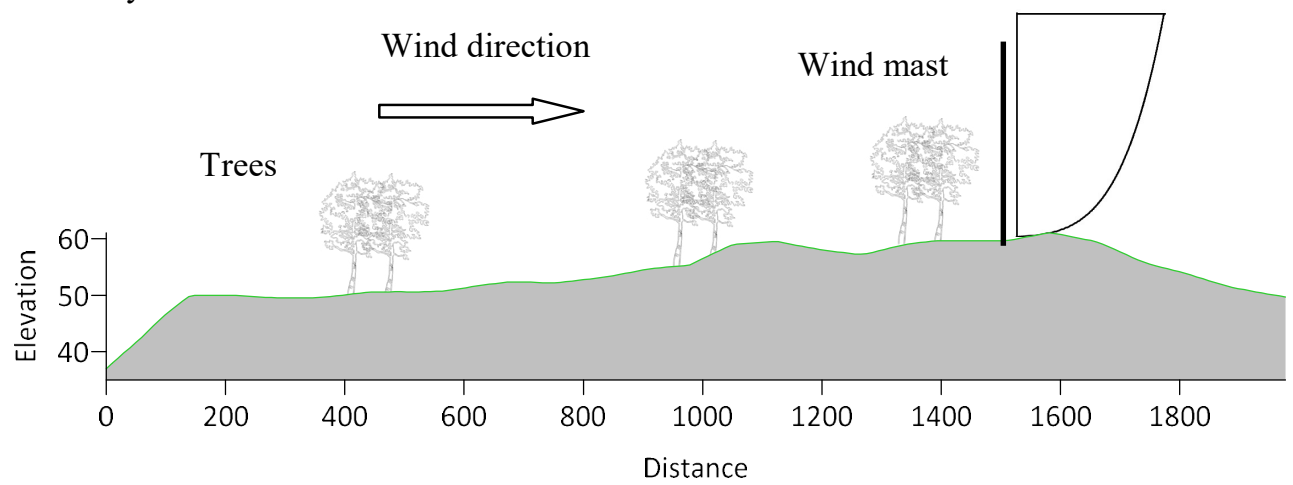

Fig. 5. Wind shear over the terrain at the point of the mast when prevailing wind direction from North-Northwestern direction 
A comparison between the two velocity profiles in height is presented in fig. 6. The graph shows that in the range of the windbreaker trees will be affected (distorted) lowpower wind turbines, respectively with a small tower - up to $50 \mathrm{~m}$. In addition, the nature of the flow will be disturbed at a distance of up to $200 \mathrm{~m}$ after the respective obstacle (at an obstacle height of $20 \mathrm{~m}$ ).

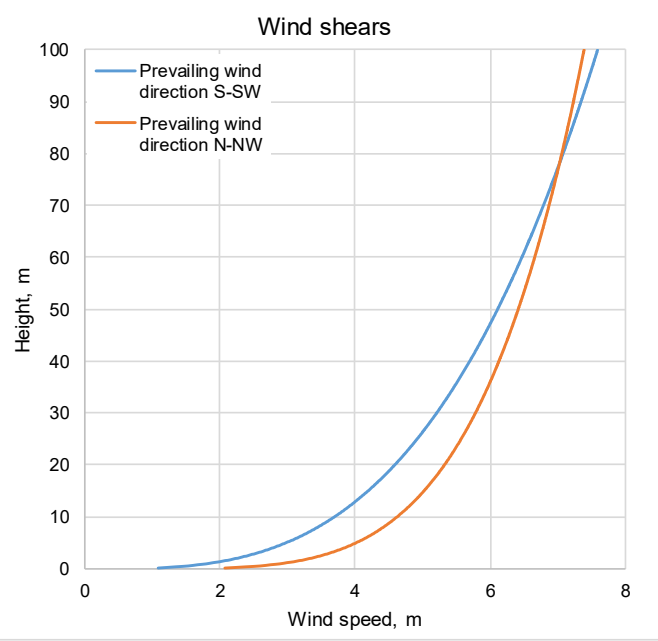

Fig. 6. Wind shears in the vicinity of mast in terms of prevailing wind directions

\section{Conclusion}

The paper examines the influence of low windbreaker trees (20 $\mathrm{m} \mathrm{high)}$ on the change in wind speed profile in height. The performed long-term measurements with a tall meteorological mast show two predominant wind directions - N-NW and S-SW. With the adopted direction from the south-southwest, the wind passes through the windbreaker trees at a distance of about $1.5 \mathrm{~km}$ before reaching the mast. At the specified distance, no influence of the speed profile from the tree shield is observed. With north-northwest prevailing direction, the wind passes unaffectedly through three tree missives, which are at a distance of about $500 \mathrm{~m}$ from each other, the latter being at a distance of $80 \mathrm{~m}$ from the mast. The deformation of the profile is observed, especially in the area of the surface boundary layer, which leads to a lower wind speed in height. However, above $50 \mathrm{~m}$ above the ground, the influence of windbreaker trees can be assessed as insignificant. Thus, in cases where the turbines are less than $50 \mathrm{~m}$ high or are located near the wind belt, their productivity will be reduced.

The study was supported by the Research and Development Sector at the Technical University of Sofia under project 202ПД0015-02.

\section{References}

1. R. Kumar, T. Stallard, P. K. Stansby, Assessment of WRF prediction of velocity profile and turbulence intensity by comparison to field measurement, (2017), Proceedings of the International Offshore and Polar Engineering Conference, pp. 215221 
2. A. Terziev, Analysis of the possibilities of using reference wind measurements in the calculation of energy production from wind farms on low complex terrains, (2019) E3S Web of Conferences, 112, pp. 1-11.

3. A. Terziev, Y. Panteleev, M. Ivanov, Possibility analysis for the use of remote reference wind, measurements, in the evaluation of energy production from low complex terrains, (2020) 2020 7th International Conference on Energy Efficiency and Agricultural Engineering, EE and AE 2020 - Proceedings, art. no. 9278994

4. P. Sharma, A. Gautam, P. Baredar, V. Warudkar, J. L. Bhagoria, S. Ahmed, Analysis of terrain of site Mamatkheda Ratlam through wind modeling tool ArcGIS and WAsP, Materials Today: Proceedings, (2020).

5. J. Vermeir, M. Runacres, T. De Troyer, CFD modelling and measurements of the atmospheric boundary layer for micrositing of small wind turbines, (2012) European Wind Energy Conference and Exhibition 2012, EWEC 2012, 2, pp. 716-725.

6. M. Salim, K. Schlünzen, D. Grawe, Including trees in the numerical simulations of the wind flow in urban areas: Should we care?, Journal of Wind Engineering and Industrial Aerodynamics, 144, (2015), p.p. 84-95

7. Yu Lun, A. Mochida, S. Murakami, H. Yoshino, T. Shirasawa, Numerical simulation

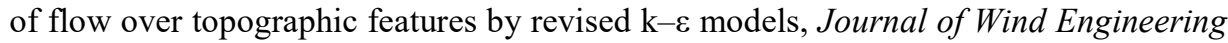
and Industrial Aerodynamics, 91, Issues 1-2, (2003), p.p. 231-245

8. L. Kang, X. Zhou, T. van Hooff, B. Blocken, M. Gu, CFD simulation of snow transport over flat, uniformly rough, open terrain: Impact of physical and computational parameters, Journal of Wind Engineering and Industrial Aerodynamics, 177, (2018), p.p. 213-226 